\title{
Isoprenylated Flavonoids with PTP1B Inhibition from Macaranga denticulata
}

\author{
Lai-Bin Zhang $\cdot$ Chun Lei $\cdot$ Li-Xin Gao $\cdot$ \\ Jing-Ya Li $\cdot$ Jia Li $\cdot$ Ai-Jun Hou
}

Received: 1 December 2015/ Accepted: 15 December 2015/Published online: 20 January 2016

(C) The Author(s) 2016. This article is published with open access at Springerlink.com

\begin{abstract}
Three new C-methylated and isoprenylated chalcone derivatives, dentichalcones A-C (1-3), together with six known compounds (4-9), were isolated from the twigs and leaves of Macaranga denticulata. Their structures were elucidated by spectroscopic analysis, including 1D, 2D NMR, and MS data. The known compounds, (2E)-1-(5,7-dihydroxy-2,2,6-trimethyl-2H-benzopyran-8-yl)-3-(4-methoxyphenyl)-2-propen-1-one (4), (2E)-1-(5,7-dihydroxy-2,2-dimethyl-2 $\mathrm{H}$-benzopyran-8-yl)-3-phenyl-2-propen-1-one (5), laxichalcone (6), macarangin (7), bonanniol $\mathrm{A}$ (8), and bonannione A (9), showed inhibitory activities against protein tyrosine phosphatase 1B (PTP1B) in vitro.

Graphical Abstract Three new C-methylated and isoprenylated chalcone derivatives, dentichalcones A-C (1-3), together with six known compounds, were isolated from the twigs and leaves of Macaranga denticulata. Some compounds showed inhibitory activities against PTP1B in vitro.
\end{abstract}<smiles>Cc1c(O)c2c(c(C(=O)/C=C/c3ccc(O)cc3)c1O)OC(C)(C)C=C2</smiles>

1<smiles>Cc1c(O)c2c(c(C(=O)CCc3ccc(O)cc3)c1O)OC(C)(C)C=C2</smiles>

2<smiles>Cc1c(O)c2c(c(C(=O)/C=C/c3ccccc3)c1O)OC(C)(CO)C=C2</smiles>

3

Keywords Macaranga denticulata Euphorbiaceae $\cdot$ Isoprenylated flavonoids $\cdot$ Dentichalcones A-C $\cdot$ Protein tyrosine phosphatase 1B

\section{L.-B. Zhang · C. Lei · A.-J. Hou ( $ه)$}

Department of Pharmacognosy, School of Pharmacy, Fudan University, 826 Zhang Heng Road, Shanghai 201203, People's Republic of China

e-mail: ajhou@shmu.edu.cn

L.-B. Zhang

Department of Chinese Medicine, School of Pharmacy, Xinxiang

Medical University, 601 Jin Sui Road, Xinxiang 453003,

People's Republic of China
L.-X. Gao - J.-Y. Li · J. Li

National Center for Drug Screening, State Key Laboratory of Drug Research, Shanghai Institute of Materia Medica, Chinese Academy of Sciences, 189 Guo Shou Jing Road, Shanghai 201203, People's Republic of China 


\section{Introduction}

Isoprenylated flavonoids are a group of natural products with diverse structures and important bioactivities. A large number of new compounds have been isolated mainly from species of the Leguminosae, Moraceae, and Euphorbiaceae families, and some of the compounds showed antibacterial, antioxidant, anti-HIV, antidiabetic, and tyrosinase-inhibiting effects [1]. The genus Macaranga Thou. (Euphorbiaceae) comprises about 300 species mainly distributed in the tropical regions of Africa, Asia, Australia, and the Pacific islands [2]. The leaves of some Macaranga species have been used as folk medicine for the treatment of swellings, cuts, sores, boils, and bruises [3]. Macaranga denticulata (B1.) Muell. Arg. is a tree with rich resources in Hainan and Xishuangbanna areas of China. Its roots have been used as traditional Chinese medicine against icteric hepatitis, eczema, and epigastric pain [4]. Previous phytochemical studies on this plant resulted in the isolation of isoprenylated flavonoids and diterpenylated flavonoids or stilbenes, some of which showed antioxidant, acetylcholinesterase-inhibiting, and antiangiogenic activities [5-7].

Protein tyrosine phosphatase 1B (PTP1B) has been regarded as a promising target for treating type 2 diabetes and obesity [8]. Discovery of effective PTP1B inhibitors is one of our research interests [9-12], and a few of isoprenylated phenolics including flavonoids and Diels-Alder adducts were found to have significant PTP1B inhibitory effects $[9,10]$. In our continuing search for natural PTP1B inhibitors from plants, chemical investigations of M. denticulata were carried out. Fractionation of the ethanol extract afforded nine isoprenylated flavonoids, including three new C-methylated and isoprenylated chalcones, dentichalcones A-C (1-3), together with six known compounds, (2E)-1-(5,7-dihydroxy-2,2,6-trimethyl-2H-benzopyran-8-yl)-3-(4-methoxyphenyl)-2-propen-1-one (4), (2E)-1(5,7-dihydroxy-2,2-dimethyl-2H-benzopyran-8-yl)-3-phenyl2-propen-1-one (5), laxichalcone (6), macarangin (7), bonanniol A (8), and bonannione A (9) (Fig. 1). The isolated compounds were tested in vitro for inhibition on PTP1B enzymatic activity. Compounds 4-9 showed significant inhibitory effects. This is the first report of C-methylated and isoprenylated chalcones from the genus Macaranga. Herein, we describe the structural elucidation and biological evaluation of these compounds.

\section{Results and Discussion}

Dentichalcone A (1) was assigned the molecular formula $\mathrm{C}_{21} \mathrm{H}_{20} \mathrm{O}_{5}$ by HREIMS with an $\mathrm{m} / z 352.1308[\mathrm{M}]^{+}$(calcd for $\left.\mathrm{C}_{21} \mathrm{H}_{20} \mathrm{O}_{5}, 352.1311\right)$. The IR spectrum showed absorptions for $\mathrm{OH}\left(3417 \mathrm{~cm}^{-1}\right)$, carbonyl $\left(1625 \mathrm{~cm}^{-1}\right)$, and aromatic
(1605, 1514, and $1445 \mathrm{~cm}^{-1}$ ) moieties. The ${ }^{1} \mathrm{H}$ NMR spectrum (Table 1) displayed a hydrogen-bonded hydroxyl signal at $\delta_{\mathrm{H}} 14.62\left(1 \mathrm{H}, \mathrm{s}, \mathrm{OH}-2^{\prime}\right)$, two trans-coupled olefinic protons at $\delta_{\mathrm{H}} 8.08(1 \mathrm{H}, \mathrm{d}, J=15.6 \mathrm{~Hz}, \mathrm{H}-\alpha)$ and $7.76(1 \mathrm{H}, \mathrm{d}$, $J=15.6 \mathrm{~Hz}, \mathrm{H}-\beta)$, resonances of a 1,4-disubstituted benzene moiety at $\delta_{\mathrm{H}} 7.61(2 \mathrm{H}, \mathrm{d}, J=8.6 \mathrm{~Hz}, \mathrm{H}-2,6)$ and $6.95(2 \mathrm{H}, \mathrm{d}$, $J=8.6 \mathrm{~Hz}, \mathrm{H}-3,5)$, a methyl group at $\delta_{\mathrm{H}} 2.05\left(3 \mathrm{H}, \mathrm{s}, \mathrm{H}_{3}-7^{\prime}\right)$, and signals of a 2,2-dimethylpyran ring at $\delta_{\mathrm{H}} 6.70(1 \mathrm{H}, \mathrm{d}$, $\left.J=10.0 \mathrm{~Hz}, \mathrm{H}-1^{\prime \prime}\right), 5.59\left(1 \mathrm{H}, \mathrm{d}, J=10.0 \mathrm{~Hz}, \mathrm{H}-2^{\prime \prime}\right)$, and $1.56\left(6 \mathrm{H}, \mathrm{s}, \mathrm{H}_{3}-4^{\prime \prime}, 5^{\prime \prime}\right)$. The ${ }^{13} \mathrm{C}$ NMR spectrum (Table 1) exhibited 21 carbon signals: three methyls, eight $s p^{2}$ methines, and ten quaternary carbons including a carbonyl, eight $s p^{2}$, and one oxygenated $s p^{3}$. These NMR spectroscopic data indicated that $\mathbf{1}$ was a chalcone derivative with an isoprenoid and a C-methyl group. By interpretation of the HMBC and NOESY spectra (Fig. 2), the structure of $\mathbf{1}$ was established. The HMBC cross-peaks of $\mathrm{H}-\alpha / \mathrm{C}-\gamma, \mathrm{C}-1$ and $\mathrm{H}-\beta / \mathrm{C}-\alpha, \mathrm{C}-\gamma$, $\mathrm{C}-1, \mathrm{C}-6$ verified the presence of chalcone skeleton. The hydroxyl group at $\delta_{\mathrm{H}} 14.62$ were assigned to $\mathrm{OH}-2^{\prime}$ by the HMBC correlations of $\mathrm{OH}-2^{\prime} / \mathrm{C}-1^{\prime}, \mathrm{C}-2^{\prime}, \mathrm{C}-3^{\prime}$. The methyl group at $\delta_{\mathrm{H}} 2.05\left(\mathrm{H}_{3}-7^{\prime}\right)$ was located at $\mathrm{C}-3^{\prime}$ by the HMBC correlations of $\mathrm{H}_{3}-7^{\prime} / \mathrm{C}-2^{\prime}, \mathrm{C}-3^{\prime}, \mathrm{C}-4^{\prime}$. The 2,2-dimethylpyran group was fused at $\mathrm{C}-5^{\prime}$ and $\mathrm{C}-6^{\prime}$, as deduced from the HMBC correlations of $\mathrm{H}-1^{\prime \prime} / \mathrm{C}-4^{\prime}, \mathrm{C}-5^{\prime}, \mathrm{C}-6^{\prime}$ and $\mathrm{H}-2^{\prime \prime} / \mathrm{C}-5^{\prime}$, together with the key NOESY correlations of $\mathrm{H}_{3}-4^{\prime \prime}, 5^{\prime \prime} / \mathrm{H}-\alpha$ and $\mathrm{H}-2,6$. Thus, the structure of $\mathbf{1}$ was elucidated as (2E)-1-(5,7-dihydroxy-2,2,6-trimethyl-2H-benzopyran-8-yl)-3-(4-hydroxyphenyl)-2- propen-1-one and named dentichalcone A.

Dentichalcone B (2) was assigned the molecular formula $\mathrm{C}_{21} \mathrm{H}_{22} \mathrm{O}_{5}$ by HREIMS $\left(\mathrm{m} / \mathrm{z}, 354.1465[\mathrm{M}]^{+}\right.$; calcd for $\left.\mathrm{C}_{21} \mathrm{H}_{22} \mathrm{O}_{5}, 354.1467\right)$. Comparison of its NMR spectroscopic data (Table 1) with those of $\mathbf{1}$ showed that $\mathbf{2}$ was a dihydrochalcone derivative of $\mathbf{1}$. This was confirmed by some diagnostic signals at $\delta_{\mathrm{H}} 3.40\left(2 \mathrm{H}, \mathrm{t}, J=7.6 \mathrm{~Hz}, \mathrm{H}_{2}-\right.$ $\alpha)$ and $2.89\left(2 \mathrm{H}, \mathrm{t}, J=7.6 \mathrm{~Hz}, \mathrm{H}_{2}-\beta\right)$ and at $\delta_{\mathrm{C}} 46.6(\mathrm{C}-\alpha)$, and $30.4(\mathrm{C}-\beta)$, and $207.3(\mathrm{C}-\gamma)$ and by the HMBC correlations of $\mathrm{H}_{2}-\alpha / \mathrm{C}-\gamma, \mathrm{C}-1$ and $\mathrm{H}_{2}-\beta / \mathrm{C}-\alpha, \mathrm{C}-\gamma, \mathrm{C}-1, \mathrm{C}-6$ (Fig. 2). Thus, the structure of 2 was elucidated as 1-(5,7dihydroxy-2,2,6-trimethyl-2H-benzopyran-8-yl)-3-(4-hydroxyphenyl)propan-1-one and named dentichalcone B.

Dentichalcone $\mathrm{C}(\mathbf{3})$ was assigned the molecular formula $\mathrm{C}_{21} \mathrm{H}_{20} \mathrm{O}_{5}$ by HRESIMS $\left(\mathrm{m} / \mathrm{z} 351.1237[\mathrm{M}-\mathrm{H}]^{-}\right.$; calcd for $\mathrm{C}_{21} \mathrm{H}_{19} \mathrm{O}_{5}, 351.1238$ ). The ${ }^{1} \mathrm{H}$ and ${ }^{13} \mathrm{C}$ NMR spectra indicated the presence of a chalcone skeleton with a hydrogenbonded hydroxyl and a methyl group, which was similar to that of 1. Its NMR spectra also displayed signals of a monosubstituted benzene ring $\left[\delta_{\mathrm{H}} 7.86(2 \mathrm{H}\right.$, br $\mathrm{d}$, $J=7.3 \mathrm{~Hz}, \mathrm{H}-2,6), 7.44(3 \mathrm{H}, \mathrm{m}, \mathrm{H}-3,4,5) ; \delta_{\mathrm{C}} 136.7$ (C1), 130.8 (C-4), 129.7 (C-2, 6), and 129.5 (C-3, 5)] and resonances of a 2-hydroxymethyl-2-methylpyran moiety $\left[\delta_{\mathrm{H}} 6.79\left(1 \mathrm{H}, \mathrm{d}, J=10.0 \mathrm{~Hz}, \mathrm{H}-1^{\prime \prime}\right), 5.52(1 \mathrm{H}, \mathrm{d}\right.$, $\left.J=10.0 \mathrm{~Hz}, \quad \mathrm{H}-2^{\prime \prime}\right), \quad 3.90$ and 3.61 (each $1 \mathrm{H}, \mathrm{d}$, $\left.J=11.9 \mathrm{~Hz}, \mathrm{H}-4^{\prime \prime} \mathrm{a}, \mathrm{b}\right), 1.57\left(3 \mathrm{H}, \mathrm{s}, \mathrm{H}_{3}-5^{\prime \prime}\right) ; \delta_{\mathrm{C}} 119.7(\mathrm{C}-$ 
<smiles>Cc1c(O)c2c(c(C(=O)/C=C/c3ccc(O)cc3)c1O)OC(C)(C)C=C2</smiles>

$1 *$<smiles>Cc1c(O)c2c(c(C(=O)CCc3ccc(O)cc3)c1O)OC(C)(C)C=C2</smiles>

2*<smiles>[CH2+]C1([18OH])C=Cc2c(O)c(C)c(O)c(C(=O)/C=C/c3ccccc3)c2O1</smiles>

3*<smiles>COc1ccc(/C=C/C(=O)c2c(O)c(C)c(O)c3c2OC(C)(C)C=C3)cc1</smiles>

4<smiles>CC1(C)C=Cc2c(O)cc(O)c(C(=O)/C=C/c3ccccc3)c2O1</smiles>

5<smiles>CC1(C)C=Cc2c(O)c(C(=O)/C=C/c3ccc(O)cc3)c3c(c2O1)C=CC(C)(C)O3</smiles>

6<smiles>CC(C)=CCC/C(C)=C/Cc1c(O)cc2oc(-c3ccc(O)cc3)c(O)c(=O)c2c1O</smiles>

7

Fig. 1 Structures of compounds 1-9

$\left.\left.1^{\prime \prime}\right), 122.5\left(\mathrm{C}-2^{\prime \prime}\right), 81.5\left(\mathrm{C}-3^{\prime \prime}\right), 66.5\left(\mathrm{C}-4^{\prime \prime}\right), 22.7\left(\mathrm{C}-5^{\prime \prime}\right)\right]$. The planar structure of $\mathbf{3}$ was further constructed by the HMBC spectrum (Fig. 2). The stereochemistry at C- $3^{\prime \prime}$ could not be assigned by the available data. Thus, the structure of 3 was elucidated as (2E)-1-[5,7-dihydroxy-2(hydroxymethyl)-2,6-dimethyl-2H-benzopyran-8-yl]-3-phenyl-2-propen-1-one and named dentichalcone $\mathrm{C}$.

The known compounds were identified as (2E)-1(5,7-dihydroxy-2,2,6-trimethyl-2H-benzopyran-8-yl)-3-(4methoxyphenyl)-2-propen-1-one (4) [13], (2E)-1-(5,7-dihydroxy-2,2-dimethyl-2H-benzopyran-8-yl)-3-phenyl-2-propen-1-one (5) [14], laxichalcone (6) [15], macarangin (7) [7], bonanniol A (8) [16], and bonannione A (9) [16] (Fig. 1) by comparison of their spectroscopic data with those reported. Compound 4 was a new natural product, which was previously reported as a synthetic molecule [13].

All the isolated compounds were tested in vitro for the inhibitory effects on PTP1B. Compounds 4-9 showed inhibition with $\mathrm{IC}_{50}$ values ranging from $14.0 \pm 1.2$ to $48.8 \pm 5.5 \mu \mathrm{M}$ (Table 2). Oleanolic acid, an effective natural PTP1B inhibitor [17], was used as the positive control $\left(\mathrm{IC}_{50}=2.6 \pm 0.6 \mu \mathrm{M}\right)$.

In summary, this is the first report of C-methylated and isoprenylated chalcones from the genus Macaranga. This class of compounds is distributed limitedly in the family Euphorbiaceae, and only Mallotus philippinensis was reported to produce $\mathrm{C}$-methylated or both $\mathrm{C}$-methylated and isoprenylated chalcones [18-21]. The Macaranga and Mallotus genera are monophyletic sister groups in the family Euphorbiaceae, which show a remarkable resemblance in their phylogeny, habit, and geographical distribution [22]. The present study indicates that the two genera also have some similarity in their secondary metabolites. Furthermore, isoprenylated flavonoids as potent PTP1B inhibitors for the therapy of obesity and type 2 diabetes need further studies. 
Table $1{ }^{1} \mathrm{H}$ and ${ }^{13} \mathrm{C}$ NMR spectroscopic data of compounds 1-3 (in acetone- $d_{6}$ )

\begin{tabular}{|c|c|c|c|c|c|c|}
\hline \multirow[t]{2}{*}{ Position } & \multicolumn{2}{|l|}{$\mathbf{1}^{\mathrm{a}}$} & \multicolumn{2}{|l|}{$2^{\mathrm{a}}$} & \multicolumn{2}{|l|}{$3^{\mathrm{a}}$} \\
\hline & $\delta_{\mathrm{C}}$ & $\delta_{\mathrm{H}}(J$ in $\mathrm{Hz})$ & $\delta_{\mathrm{C}}$ & $\delta_{\mathrm{H}}(J$ in $\mathrm{Hz})$ & $\delta_{\mathrm{C}}$ & $\delta_{\mathrm{H}}(J$ in $\mathrm{Hz})$ \\
\hline 1 & 128.0 & & 133.2 & & 136.7 & \\
\hline 2,6 & 131.1 & $7.61, \mathrm{~d}(8.6)$ & 130.0 & $7.10, \mathrm{~d}(8.3)$ & 129.7 & 7.86, br d $(7.3)$ \\
\hline 3,5 & 116.9 & $6.95, \mathrm{~d}(8.6)$ & 116.0 & $6.75, \mathrm{~d}(8.3)$ & 129.5 & $7.44, \mathrm{~m}$ \\
\hline 4 & 160.7 & & 156.4 & & 130.8 & $7.44, \mathrm{~m}$ \\
\hline$\alpha$ & 125.1 & $8.08, \mathrm{~d}(15.6)$ & 46.6 & $3.40, \mathrm{t}(7.6)$ & 129.0 & $8.54, \mathrm{~d}(15.5)$ \\
\hline$\beta$ & 143.4 & $7.76, \mathrm{~d}(15.6)$ & 30.4 & $2.89, \mathrm{t}(7.6)$ & 142.7 & $7.75, \mathrm{~d}(15.5)$ \\
\hline$\gamma$ & 193.5 & & 207.3 & & 194.0 & \\
\hline $1^{\prime}$ & 106.4 & & 105.9 & & 106.4 & \\
\hline $2^{\prime}$ & 165.4 & & 164.4 & & 165.5 & \\
\hline $3^{\prime}$ & 104.4 & & 104.2 & & 104.4 & \\
\hline $4^{\prime}$ & 158.2 & & 158.0 & & 158.6 & \\
\hline $5^{\prime}$ & 103.2 & & 102.9 & & 103.3 & \\
\hline $6^{\prime}$ & 154.9 & & 155.4 & & 155.0 & \\
\hline $7^{\prime}$ & 7.8 & $2.05, \mathrm{~s}^{\mathrm{b}}$ & 7.7 & $2.05, \mathrm{~s}^{\mathrm{b}}$ & 7.8 & $2.06, \mathrm{~s}^{\mathrm{b}}$ \\
\hline $1^{\prime \prime}$ & 117.8 & $6.70, \mathrm{~d}(10.0)$ & 117.6 & $6.65, \mathrm{~d}(10.0)$ & 119.7 & $6.79, \mathrm{~d}(10.0)$ \\
\hline $2^{\prime \prime}$ & 125.8 & $5.59, \mathrm{~d}(10.0)$ & 125.8 & $5.53, \mathrm{~d}(10.0)$ & 122.5 & $5.52, \mathrm{~d}(10.0)$ \\
\hline $3^{\prime \prime}$ & 78.2 & & 78.3 & & 81.5 & \\
\hline $4^{\prime \prime}$ & 27.8 & $1.56, \mathrm{~s}$ & 27.7 & $1.44, \mathrm{~s}$ & 66.5 & $\begin{array}{l}3.90, \mathrm{~d}(11.9) \\
3.61, \mathrm{~d}(11.9)\end{array}$ \\
\hline $5^{\prime \prime}$ & 27.8 & $1.56, \mathrm{~s}$ & 27.7 & $1.44, \mathrm{~s}$ & 22.7 & $1.57, \mathrm{~s}$ \\
\hline $\mathrm{OH}-2^{\prime}$ & & $14.62, \mathrm{~s}$ & & $14.10, \mathrm{~s}$ & & $14.52, \mathrm{~s}$ \\
\hline
\end{tabular}

${ }^{\text {a }}$ Data were measured at $400 \mathrm{MHz}\left({ }^{1} \mathrm{H}\right)$ and $100 \mathrm{MHz}\left({ }^{13} \mathrm{C}\right)$

b Signals are overlapped

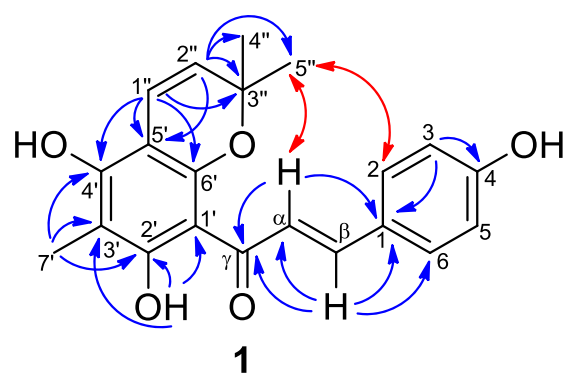

1

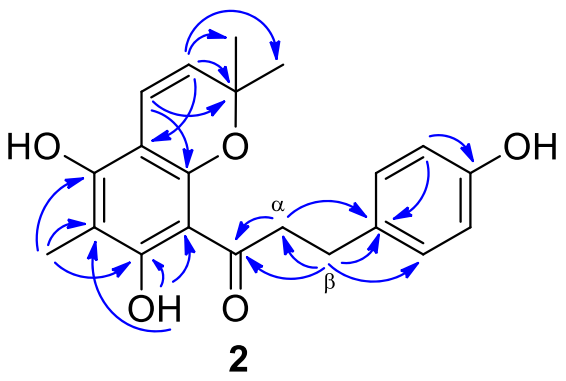

2

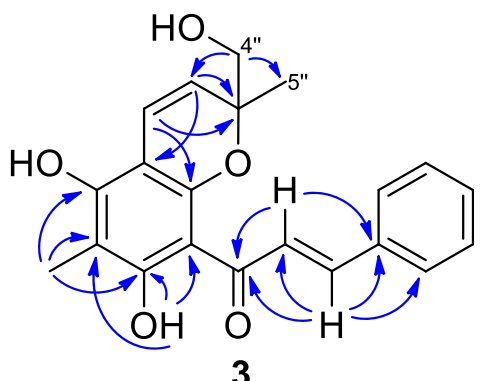

3

$\curvearrowright \mathrm{HMBC} \longleftrightarrow \mathrm{NOESY}$

Fig. 2 Selected HMBC and NOESY correlations of compounds 1-3

\section{Experimental Section}

\subsection{General Experimental Procedures}

Optical rotation was measured on a JASCO P-1030 digital polarimeter. UV spectra were recorded on a Hitachi U-2900 spectrophotometer. IR spectra were measured on a Nicolet Avatar-360 spectrometer with $\mathrm{KBr}$ pellets. NMR spectra were obtained on Varian Mercucy Plus 400 instruments. Chemical shifts were reported with TMS as internal standard or with respect to acetone- $d_{6}\left(\delta_{\mathrm{H}} 2.04, \delta_{\mathrm{C}}\right.$ $206.0 \mathrm{ppm})$. EIMS (70 eV) and HREIMS were recorded on an Agilent 5973N and a Waters Micromass GCT mass spectrometer, respectively. ESIMS and HRESIMS were performed on an Agilent 1100 LC/MSD and a Bruker Daltonics ApexIII mass spectrometer, respectively. Semipreparative HPLC was performed on an Agilent 1200 (Agilent Technologies, Palo Alto, CA, USA) and a Sepax Amethyst C18 column $(150 \times 10 \mathrm{~mm}, 5 \mu \mathrm{m}$, Sepax Techologies, Inc., Newark, DE, USA), using a UV detector 
Table 2 Inhibitory activities of compounds 4-9 against PTP1B

\begin{tabular}{lc}
\hline Compound & $\mathrm{IC}_{50} \pm \mathrm{SD}(\mu \mathrm{M})$ \\
\hline $\mathbf{4}$ & $48.8 \pm 5.5$ \\
$\mathbf{5}$ & $19.3 \pm 1.4$ \\
$\mathbf{6}$ & $20.7 \pm 5.3$ \\
$\mathbf{7}$ & $22.7 \pm 4.6$ \\
$\mathbf{8}$ & $15.2 \pm 2.8$ \\
$\mathbf{9}$ & $14.0 \pm 1.2$ \\
Oleanolic acid & $2.6 \pm 0.6$ \\
\hline
\end{tabular}

set at $210 \mathrm{~nm}$. Column chromatography (CC) was performed on silica gel (200-300 mesh, Yantai Institute of Chemical Technology, Yantai, People's Republic of China), Diaion HP-20 (Mitsubishi Chemical Co., Tokyo, Japan), and Sephadex LH-20 gel (GE Healthcare Amersham Biosciences, Uppsala, Sweden). Fractions were monitored by TLC analysis run on precoated silica gel GF254 plates (10-40 $\mu \mathrm{m}$, Yantai Institute of Chemical Technology, Yantai, People's Republic of China).

\subsection{Plant Material}

The twigs and leaves of $M$. denticulata were collected in Hekou County, Yunnan Province, People's Republic of China, in April 2011. The plant material was identified by Dr. Qin-Shi Zhao, Kunming Institute of Botany, Chinese Academy of Sciences, and a voucher specimen (TCM 11-04-15 Hou) has been deposited at the Herbarium of the Department of Pharmacognosy, School of Pharmacy, Fudan University.

\subsection{Extraction and Isolation}

The milled, air-dried twigs and leaves of $M$. denticulata $(5.0 \mathrm{~kg})$ were percolated with $95 \% \mathrm{EtOH}$ at room temperature $(60 \mathrm{~L})$. The filtrate was evaporated under reduced pressure to give a residue $(500 \mathrm{~g})$, which was suspended in $\mathrm{H}_{2} \mathrm{O}$ and extracted with $\mathrm{CH}_{2} \mathrm{Cl}_{2}(4 \times 1 \mathrm{~L})$. The $\mathrm{CH}_{2} \mathrm{Cl}_{2}$ extract (140 g) was subjected to $\mathrm{CC}$ on Diaion HP-20 eluted with $90 \% \mathrm{EtOH}$. The $90 \% \mathrm{EtOH}$ fraction (95 g) was separated by $\mathrm{CC}$ on silica gel eluted with a gradient of petroleum ether-EtOAc $(1: 0,10: 1,5: 1,1: 1,1: 2)$ to give fractions A-J. Fraction D was separated by $\mathrm{CC}$ on Sephadex LH-20 eluted with $\mathrm{CHCl}_{3}-\mathrm{MeOH}$ (1:1) to afford fractions D1-D4. Fraction D4 was chromatographed over silica gel eluted with a gradient of petroleum ether- $\mathrm{Me}_{2} \mathrm{CO}$ (10:1, 5:1) to afford fractions D4.1-D4.5. Fraction D4.3 was purified on a Sephadex LH-20 column eluted with $\mathrm{MeOH}$ to provide 4 (100 mg). Fraction E was chromatographed by silica gel eluted with a gradient of $\mathrm{CH}_{2} \mathrm{Cl}_{2}-\mathrm{Me}_{2} \mathrm{CO}(40: 1,2: 1)$ to afford fractions E1-E8.
Fraction E4 was separated on silica gel eluted with a gradient of petroleum ether- $\mathrm{Me}_{2} \mathrm{CO}(12: 1,10: 1)$ to give fractions E4.1-E4.5. Fraction E4.5 was chromatographed by semi-preparative $\mathrm{HPLC}\left(\mathrm{CH}_{3} \mathrm{OH}-\mathrm{H}_{2} \mathrm{O}, 90: 10\right.$, flow rate $1 \mathrm{~mL} / \mathrm{min})$ to afford $6(10 \mathrm{mg})$. Fraction $\mathrm{F}$ was isolated by $\mathrm{CC}$ over Sephadex $\mathrm{LH}-20$ eluted with $\mathrm{CHCl}_{3}-\mathrm{MeOH}(1: 1)$ to afford fractions F1-F5. Fractions F2 and F4 were chromatographed over silica gel eluted with a gradient of petroleum ether-EtOAc $(10: 1,2: 1)$ to afford fractions F2.1-F2.6 and F4.1-F4.4, respectively. Fractions F2.2, $\mathrm{F} 2.4$, and F4.4 were purified by semi-preparative HPLC at flow rate $1 \mathrm{~mL} / \mathrm{min}$ to afford 2 (4 mg; $\mathrm{CH}_{3} \mathrm{OH}-\mathrm{H}_{2} \mathrm{O}$, 83:17), 9 (10 mg; $\left.\mathrm{CH}_{3} \mathrm{OH}-\mathrm{H}_{2} \mathrm{O}, 90: 10\right)$, and 7 (12 mg; $\left.\mathrm{CH}_{3} \mathrm{OH}-\mathrm{H}_{2} \mathrm{O}, 91: 9\right)$, respectively. Fraction F4.2 was separated by $\mathrm{CC}$ on Sephadex LH-20 eluted with $\mathrm{CH}_{3} \mathrm{OH}$ to provide 1 (15 mg). Fraction $\mathrm{G}$ was separated by $\mathrm{CC}$ on silica gel eluted with a gradient of $\mathrm{CH}_{2} \mathrm{Cl}_{2}-\mathrm{Me}_{2} \mathrm{CO}$ (30:1, 2:1) to give fractions G1-G7. Fractions G2, G3, and G4 were chromatographed by semi-preparative HPLC at flow rate $1 \mathrm{~mL} / \mathrm{min}$ to yield $\mathbf{5}$ (2 $\left.\mathrm{mg} ; \mathrm{CH}_{3} \mathrm{OH}-\mathrm{H}_{2} \mathrm{O}, 88: 12\right), 3$ (3 mg; $\left.\mathrm{CH}_{3} \mathrm{OH}-\mathrm{H}_{2} \mathrm{O}, 80: 20\right)$, and 8 (12 mg; $\mathrm{CH}_{3} \mathrm{OH}-\mathrm{H}_{2} \mathrm{O}$, $88: 12)$, respectively.

\subsection{Dentichalcone A (1)}

Red, amorphous powder; UV $(\mathrm{MeOH}) \lambda_{\max }(\log \varepsilon) 229$ (4.43), 244 (4.42) (sh), 289 (4.30), 368 (4.66) nm; IR (KBr) $v_{\max } 3417,2972,2915,1625,1605,1541,1514,1445$, 1167, 830, $536 \mathrm{~cm}^{-1} ;{ }^{1} \mathrm{H} \mathrm{NMR}$ and ${ }^{13} \mathrm{C} \mathrm{NMR}$ data, see Table 1; EIMS m/z $352\left[\right.$ [M] $^{+}$(30), 337 (64), 217 (100), 91 (15), 77 (7); HREIMS $m / z, 352.1308\left[\mathrm{M}^{+}\right.$(calcd for $\left.\mathrm{C}_{21} \mathrm{H}_{20} \mathrm{O}_{5}, 352.1311\right)$.

\subsection{Dentichalcone B (2)}

Yellow, amorphous powder; UV (MeOH) $\lambda_{\max }(\log \varepsilon) 222$ (3.79), 284 (3.82) nm; IR (KBr) $v_{\max } 3419,2975,2924$, 1638, 1606, 1515, 1427, 1218, 1165, 1133, 827, $548 \mathrm{~cm}^{-1}$; ${ }^{1} \mathrm{H}$ NMR and ${ }^{13} \mathrm{C}$ NMR data, see Table 1 ; EIMS $m / z 354$ $[\mathrm{M}]^{+}$(49), 339 (100), 233 (35), 219 (33), 191 (36), 107 (47), 91 (16), 77 (21), 65 (8), 43 (8); HREIMS m/z $354.1465[\mathrm{M}]^{+}$(calcd for $\mathrm{C}_{21} \mathrm{H}_{22} \mathrm{O}_{5}, 354.1467$ ).

\subsection{Dentichalcone C (3)}

Red, amorphous powder; $[\alpha]_{\mathrm{D}}^{25}-32.9$ ( $c$ 0.30, MeOH); UV $(\mathrm{MeOH}) \lambda_{\max }(\log \varepsilon) 224$ (4.33), 240 (4.26), 287 (4.30), 346 (4.41) nm; IR (KBr) $v_{\max } 3420,2975,2915,1633$, 1595, 1456, 1348, 1171, 1130, 701, $575 \mathrm{~cm}^{-1} ;{ }^{1} \mathrm{H} \mathrm{NMR}$ and ${ }^{13} \mathrm{C}$ NMR data, see Table 1; ESIMS $m / z 351[\mathrm{M}-\mathrm{H}]^{-}$; HRESIMS $m / z 351.1237[\mathrm{M}-\mathrm{H}]^{-}$(calcd for $\mathrm{C}_{21} \mathrm{H}_{19} \mathrm{O}_{5}$, 351.1238). 


\subsection{Assay of PTP1B Activity}

The bioassay procedure was the same as that reported previously $[10,23]$. The result of PTP1B inhibition was expressed as $\mathrm{IC}_{50}$, which was calculated with Prism 4 software (Graphpad, San Diego, CA).

Acknowledgments Financial support from the National Natural Science Foundation of China (Nos. 81222045, 21372049), the Specialized Research Fund for the Doctoral Program of Higher Education of China (20130071120104), and the Shu Guang Project (No. 12SG02) from Shanghai Municipal Education Commission and Shanghai Education Development Foundation is gratefully acknowledged.

\section{Compliance with ethical standards}

Conflict of interest The authors declare no conflict of interest.

Open Access This article is distributed under the terms of the Creative Commons Attribution 4.0 International License (http:// creativecommons.org/licenses/by/4.0/), which permits unrestricted use, distribution, and reproduction in any medium, provided you give appropriate credit to the original author(s) and the source, provide a link to the Creative Commons license, and indicate if changes were made.

\section{References}

1. B. Botta, A. Vitali, P. Menendez, D. Misiti, G.D. Monache, Curr. Med. Chem. 12, 713-739 (2005)

2. G. Webster, Ann. Missouri Bot. Garden 81, 33-144 (1994)

3. A. Nick, T. Rali, O. Sticher, J. Ethnopharmacol. 49, 147-156 (1995)

4. S.J. Wei, J. Guangxi. Tradit. Chin. Med. 15, 36-39 (1992)
5. D.S. Yang, Z.L. Li, X. Wang, H. Yan, Y.P. Yang, H.R. Luo, K.C. Liu, W.L. Xiao, X.L. Li, RSC Adv. 5, 13886-13890 (2015)

6. D.S. Yang, Z.L. Li, W.B. Peng, Y.P. Yang, X. Wang, K.C. Liu, X.L. Li, W.L. Xiao, Fitoterapia 103, 165-170 (2015)

7. S. Sutthivaiyakit, S. Unganont, P. Sutthivaiyakit, A. Suksamrarn, Tetrahedron 58, 3619-3622 (2002)

8. B.J. Goldstein, A. Bittner-Kowalczyk, M.F. White, M. Harbeck, J. Biol. Chem. 275, 4283-4289 (2000)

9. M. Wang, L.X. Gao, J. Wang, J.Y. Li, M.H. Yu, J. Li, A.J. Hou, Phytochemistry 109, 140-146 (2015)

10. M. Wang, B.W. Yu, M.H. Yu, L.X. Gao, J.Y. Li, H.Y. Wang, J. Li, A.J. Hou, Chem. Biodivers. 12, 937-945 (2015)

11. C.C. Liu, C. Lei, Y. Zhong, L.X. Gao, J.Y. Li, M.H. Yu, J. Li, A.J. Hou, Tetrahedron 70, 4317-4322 (2014)

12. H.B. Liao, C. Lei, L.X. Gao, J.Y. Li, J. Li, A.J. Hou, Org. Lett. 17, 5040-5043 (2015)

13. L. Xia, Y.R. Lee, Bull. Korean Chem. Soc. 32, 2921-2927 (2011)

14. A.G. Kanthasamy, G.A. Kraus, V. Anantharam, U. S. Pat. Appl. Publ. US 20110112182 A1 20110512 (2011)

15. Y.L. Lin, Y.L. Chen, Y.H. Kuo, Chem. Pharm. Bull. 40, 2295-2299 (1992)

16. M. Bruno, G. Savona, L. Lamartina, F. Lentini, Heterocycles 23, 1147-1153 (1985)

17. Y.N. Zhang, W. Zhang, D. Hong, L. Shi, Q. Shen, J.Y. Li, J. Li, L.H. Hu, Bioorg. Med. Chem. 16, 8697-8705 (2008)

18. R.R. Kulkarnia, S.G. Tupeb, S.P. Gamplec, M.G. Chandgudea, D. Sarkarc, M.V. Deshpandeb, S.P. Joshia, Nat. Prod. Res. 28, 245-250 (2014)

19. A. Daikonya, S. Katsuki, S. Kitanaka, Chem. Pharm. Bull. 52, 1326-1329 (2004)

20. T. Tanaka, T. Ito, M. Iinuma, Y. Takahashi, H. Naganawa, Phytochemistry 48, 1423-1427 (1998)

21. M. Furusawa, Y. Ido, T. Tanaka, T. Ito, K. Nakaya, I. Ibrahim, M. Ohyama, M. Iinuma, Y. Shirataka, Y. Takahashi, Helv. Chim. Acta 88, 1048-1058 (2005)

22. K.K.M. Kulju, S.E.C. Sierra, S.G.A. Draisma, R. Samuel, P.C. van Welzen, Am. J. Bot. 94, 1726-1743 (2007)

23. L. Shi, H.P. Yu, Y.Y. Zhou, J.Q. Du, Q. Shen, J.Y. Li, J. Li, Acta Pharmacol. Sin. 29, 278-284 (2008) 